\title{
A produção discursiva sobre ensino de língua portuguesa: análise de dissertações de mestrado
}

\author{
Daniela Aparecida Eufrásio ${ }^{1}$ \\ ORCID: 0000-0002-5729-9221 \\ Valdir Heitor Barzotto ${ }^{2}$ \\ ORCID: 0000-0003-1564-9550
}

\section{Resumo}

Este artigo apresenta uma análise discursiva de dissertações de mestrado que tratam do ensino de língua portuguesa na educação básica, defendidas entre 2001 e 2017, em distintas universidades do país. 0 objetivo da pesquisa foi avaliar, no corpus, as regularidades discursivas que lhe eram subjacentes, de acordo com a concepção foucaultiana de que todo discurso responde a determinadas condições de produção, a certas regras de funcionamento que definem o que é legítimo enquanto circulação de saberes que, por sua vez, sustentarão práticas diversas, dentre elas a científica. Metodologicamente, nossa investigação define-se como bibliográfıca, caracterizada por procedimentos que não se limitam à revisão da literatura. Os resultados demonstraram que a negação polêmica constitui o discurso analisado, configurando-se na descrição e apresentação de situações de ensino de português que só existem enquanto criação científica. Avaliamos que tais realidades criadas respondem a concepções teórico-metodológicas de ensino de português balizadas pelos trabalhos em questão e que são apresentadas como forma de refutação ao que foi observado em práticas escolares do ensino básico. Observou-se, assim, um modus operandi em dissertações de mestrado, que abordam o ensino de português, caracterizado pela polêmica instaurada na reiteração da inexistência, nos contextos escolares observados, de situações de ensino de língua tidas como ideais.

\section{Palavras-chave}

Ensino da língua portuguesa - Produção do conhecimento - Análise de discurso.

1- Universidade Federal de Alfenas, Alfenas, MG, Brasil. Contato: daniela.eufrasio@unifal-mg.edu.br; danielaeufrasio@gmail.com.

2- Universidade de São Paulo, São Paulo, SP, Brasil. Contato: barzotto@usp.br. 


\section{The discursive production related to the teaching of Portuguese language: analysis of Master's dissertations}

\section{Abstract}

This paper presents a discursive analysis of Master's dissertations that address the teaching of Portuguese language in basic education, defended between 2001 and 2017, in different universities of the country. The objective of the research was to evaluate, in the corpus, the underlying discursive regularities, according to Foucault's conception that every discourse responds to certain conditions of production, to certain operating rules that define what is legitimate as circulation of knowledge that, in turn, will sustain various practices, including scientific practices. Methodologically, our investigation is defined as bibliographic, characterized by procedures that are not limited to the literature review. The results showed that the polemic denial constitutes the discourse analyzed, setting itself in the description and presentation of Portuguese teaching situations that exist only as a scientific creation. For us, these created realities respond to theoretical and methodological conceptions of Portuguese teaching defended by the dissertations analyzed and which are presented as a form of refutation to what was observed in school practices of basic education. Thus, a modus operandi was observed in Master's dissertations, which address the teaching of Portuguese, whose hallmark is the controversy set by the reiteration of the lack, in the school contexts observed, of situations of language teaching seen as ideals.

\section{Keywords}

Portuguese language teaching - Knowledge production - Discourse analysis.

\section{Introdução}

Este artigo propõe uma análise discursiva da produção científico-acadêmica sobre ensino de língua portuguesa, tratando, especificamente, de dissertações de mestrado. As produções analisadas foram localizadas no Banco de Teses da CAPES (Coordenação de Aperfeiçoamento de Pessoal de Nivel Superior) e todas elas atendem ao critério de terem como assunto o ensino de português na educação básica ${ }^{3}$.

\footnotetext{
3- Este artigo é um desdobramento dos resultados apresentados, inicialmente, na pesquisa de doutorado da autora (EUFRÁSIO, 2013). Acrescem-se algumas reflexões proporcionadas por pesquisa coletiva a respeito da formação do professor de português. Como os autores atuam como docentes e pesquisadores nessa formação, ao longo do texto vão manter a ideia de pesquisa em andamento, entendida como manutenção da preocupação em aprofundar os conhecimentos a respeito do tema. 0 tempo da pesquisa, entendida desse modo, não é, para nós, idêntico à duração de um doutorado ou à duração de um projeto estabelecidos em regulamentos próprios. Em função disso, ao longo do texto referimo-nos aos tempos dos empreendimentos de pesquisa já concluídos, ao tempo presente da escrita do texto e à indicação de pesquisas futuras.
} 
Assumimos como pressuposto a caracterização de discurso como uma produção regulada (FOUCAULT, 2004, 2005), ou seja, enquanto enunciação que constitui os seus sentidos não somente em referência ao momento em que é produzido, mas que, no momento mesmo de sua produção, responde a um conjunto de discursos que determinam os dizeres que lhe são ou não cabíveis, de modo a atribuir-lhe um estatuto de legítimo ou ilegítimo.

Entende-se, assim, que o discurso não é livremente produzido, como se respondesse somente ao desejo individual de expressão, mas ele é regulamentado por diversos fatores que delimitam as suas condições de produção.

Tais condições conferem sentidos considerando-se: a) dada posição históricosocial que é ocupada por quem enuncia; b) certos referenciais que delimitam o que é possível enunciar; c) um campo discursivo constituído por relações de continuidade e/ ou complementaridade quanto ao que se enuncia; e d) um status referente ao grau de reincidência do que foi enunciado. (FOUCAULT, 2005).

Considera-se, assim, que a ordem do discurso tem "uma função normativa e reguladora” (REVEL, 2005, p. 37). Conforme Foucault (2005, p. 132-133), o discurso:

[...] não forma uma unidade retórica ou formal, indefinidamente repetível e cujo aparecimento ou utilização poderíamos assinalar [...]; é constituído de um número limitado de enunciados para os quais podemos definir um conjunto de condições de existência.

Nos embates travados no e pelo discurso, há tentativas de limitar os enunciados e de expandi-los de modo que certas verdades apareçam. Para ilustrar, recorremos ao enunciado proferido pela personagem Milada Horáková, uma presa política que é levada a assinar uma confissão de culpa, mas, quando indagada em julgamento se fez o que estava escrito, responde: “- Sou culpada de tudo o que confessei. No entanto, não acredito que seja nenhum crime”. Mais adiante responde: “- Sim, sou culpada disso” (MILADA, 2017). Há, portanto, um embate entre o controle dos enunciados e o alcance de seus significados. Após o julgamento, é condenada à morte.

Entender os embates e os sentidos presentificados na produção discursiva a respeito do ensino de português em contextos de educação escolar levou-nos a interrogar que regularidades caracterizam as relações de contiguidade, complementaridade, reiteração entre os enunciados que formam a produção discursiva que trata desse ensino e que oposições estabelecem com outros discursos. A análise de 20 dissertações de mestrado, conforme passamos a detalhar, é representativa de como essa produção discursiva constitui-se.

\section{Formação e atuação do professor de português sob enfoque}

A fim de situar o corpus da pesquisa, constituído por dissertações de mestrado, como mencionado anteriormente, citamos 0 Plano Nacional de Pós-Graduação (PNPG 2011-2020) da CAPES, no qual estão expostos dados que demonstram como a produção acadêmica no Brasil apresentou efetiva expansão. De acordo com as informações disponibilizadas, os cursos de mestrado acadêmico recomendados e habilitados para funcionamento, em todas as áreas do conhecimento, estão em evolução quantitativa 
desde 1976. A formação no mestrado contava aproximadamente com 500 cursos nesse ano e atingiu, em $2009^{4}$, o total de 2.436 cursos, representando um crescimento da ordem de 370\% (BRASIL, 2010, p. 47).

Em consequência da ampliação da oferta de tais cursos, houve um considerável aumento no número de titulações. Em termos nacionais, verifica-se que, de 3.665 titulados mestres, no ano de 1987, foi-se, em 2009, para 35.698 titulações, o que representou um crescimento de 874\% (BRASIL, 2010, p. 66).

0 relatório final de acompanhamento do primeiro quinquênio do PNPG (Plano Nacional de Pós-Graduação) 2011-2020, publicado em fevereiro de 2017, apresenta atualizações desses dados. Em conformidade com esse documento, o número de cursos de mestrado subiu para 3.238, em 2015, com projeção de chegar a 3.911 em 2020. Quanto à titulação, em 2015, obtiveram o título de mestre 46.517 alunos e a projeção é que se chegue, em 2020, a 58.169 titulados (BRASIL, 2017).

0 aumento na produção dessas dissertações caracteriza-as como uma fonte importante de pesquisa no que concerne à análise do discurso científico-acadêmico, viabilizando, como no caso do presente artigo, a análise de regularidades, ou seja, de invariantes que, na aparente dispersão dos discursos produzidos, configuram mesmos conteúdos e formas de abordagem em relação a um dado assunto. Esse tipo de investigação dá a ver a tensão entre, de um lado, o conjunto múltiplo de trabalhos acadêmicos produzidos e, de outro, o que se apresenta como recorrente/constituinte nessa produção discursiva.

A análise das dissertações que compuseram o corpus indiciou regularidades que propiciam uma continuidade da presente pesquisa, no sentido de se avaliar outras produções, como teses de doutorado, por exemplo, que se voltem para o ensino de português e ao ensino de outros conteúdos. A possível ampliação do escopo de pesquisa permitirá examinar se as recorrências discursivas se restringem ao campo de estudos e de pesquisa do ensino de português ou se também comparecem em outros discursos que tratam de temas da Educação $0^{5}$.

0 que expomos do corpus não pretende apresentar-se como expressão da totalidade de produções científico-acadêmicas acerca do ensino de português na educação básica. Longe disso, transcrevemos excertos do material analisado com o objetivo de, conforme exposto anteriormente, indiciar regularidades discursivas que constituem a produção sob enfoque e sinalizar a relevância de avaliar-se o alcance dessa regularidade em termos qualitativos em diferentes pesquisas da área da educação, a fim de que possamos, pelo próprio exercício investigativo, contribuir para que se identifiquem as configurações disciplinares do campo de produção científico-acadêmica em que nos incluímos.

Ao todo, analisamos 20 dissertações de mestrado, defendidas, no período de 2001 a 2017, em instituições das cinco regiões do país. Tais produções atenderam aos critérios de estarem vinculadas a instituições universitárias públicas brasileiras, de apresentarem como assunto o ensino de língua portuguesa na educação básica e de estarem integralmente disponíveis para acesso on-line. Esse recorte de pesquisa também se apresentou em

4- 0 documento citado da CAPES apresenta estatísticas que abarcam o período de 1976 a 2009.

5- Nossa impressão é a de que algumas regularidades discursivas constituem as pesquisas na área de educação de um modo global, seja na referência ao ensino de português, de matemática, de ciências e assim por diante. 
consonância com o Projeto Disciplinas da Licenciatura voltadas para o ensino de língua portuguesa $^{6}$, a partir do qual os autores deste artigo, em conjunto com outros pesquisadores da área, investigaram a formação do professor de língua portuguesa, no que diz respeito ao seu referencial teórico-metodológico, quadro proposicional e constructo conceitual, dentre outros aspectos, que caracterizavam disciplinarmente o ensino de português.

A fim de apresentar o cenário de discussão gerado a partir da problemática acerca do que disciplinarmente sustenta-se como legítimo quanto ao ensino de português em escolas da educação básica, citamos, a seguir, publicações que dão mostras das diferentes esferas de análise e avaliação dos discursos que envolvem a atuação e a formação dos docentes de língua materna.

0 livro Formação de professor de língua portuguesa: quando a linguagem e o ensino se encontram (SOUSA; BARZOTTO; SAMPAIO, 2010) apresenta resultados parciais do projeto de pesquisa citado anteriormente. Nele, Barzotto (2010) questiona o fazer científico que fica cristalizado à repetição do saber legitimado pela área. Quanto a isso, o autor apresenta um dado interessante que remete a um relatório de qualificação de mestrado. A aluna de programa de pós-graduação, que trazia no seu histórico a atuação como professora da rede básica por 14 anos, ao citar no seu relatório um renomado autor da área, reproduz a seguinte afirmação "Os professores não trabalham com leitura". Ocorre que, no mesmo documento, ela descreveu como, enquanto docente, praticou o ensino de leitura com suas turmas de escolas da educação básica.

Esse dado aponta para um dos focos motivadores da presente pesquisa, bem como das demais mencionadas, que se volta para a tensão entre considerar o saber acumulado e produzir conhecimentos. Em A ordem do discurso (FOUCAULT, 2004), a disciplina é apresentada como parte do fazer científico e é definida enquanto um princípio, segundo o qual é possível construir novos saberes, contanto que eles correspondam às delimitações legitimadas no interior da própria área de saber a que se pretende pertencer.

Na publicação anteriormente citada (SOUSA; BARZOTTO; SAMPAIO, 2010), Souza (2010, p. 34) ajuda a situar esse debate quando afirma o que segue:

A história da ciência introduziu com muita força, no século XVIII, o problema não somente da natureza do pensamento racional, do seu fundamento e do seu direito, mas também a questão da sua história e da sua geografia [...]. É o conjunto das práticas discursivas e não-discursivas que faz com que uma coisa entre no jogo do verdadeiro ou falso e o constitui como objeto para o pensamento.

A investigação acerca da configuração disciplinar das licenciaturas voltadas para o ensino de português, tendo em vista o tensionamento citado, produziu diferentes resultados, conforme continuamos a destacar no que segue. Almeida (2010), a partir da

\footnotetext{
6- Esse projeto de pesquisa ocorreu em cooperação interinstitucional de universidades de diferentes estados (Universidade de São Paulo - USP, Universidade Federal de Alfenas - UNIFAL-MG, Universidade Estadual do Rio Grande do Norte - UERN, Universidade Federal do Maranhão - UFMA), no período de 2008 a 2013, contando com o apoio da Fundação de Amparo à Pesquisa do Estado de Minas Gerais - FAPEMIG, da Fundação de Amparo à Pesquisa do Estado do Maranhão - FAPEMA e da CAPES. Em 2014, ainda se produziu o relatório final e, como vários dos integrantes do projeto são, ou tornaram-se durante sua vigência, professores de disciplinas que tematizam o ensino de português, as pesquisas continuam.
} 
análise de projetos pedagógicos de cursos de Licenciatura em Letras de Instituições do Ensino Superior do Maranhão, apontou para o esvaziamento do que é próprio a essa formação em nome de um discurso generalista. Conforme percebido nos documentos analisados, "Tudo o que se dirigiria para a escola, a aula, a relação professor/aluno, a formação de professor, se generalizou para outro lugar, amplo e geral: a sociedade, a realidade, o mundo" (ALMEIDA, 2010, p. 136).

No livro Professor de português: como se forma, trabalha e entende sua prática (RIOLFI, 2015), a investigação do campo de regularidades constituintes do ensino de português levou a análises que, dentre outros resultados, apontaram para: a) um conjunto de proposições a respeito do ensino de leitura comum nas aulas de professores responsáveis por ministrar metodologia do ensino de língua portuguesa em cursos de letras e pedagogia em universidades públicas do país (RIOLFI; EUFRÁSIO; BAZON, 2015); b) a regularidade discursiva em relatórios de estágio produzidos por acadêmicos do curso de Letras na disciplina de metodologia do ensino com a recorrente menção a um tempo restrito para as atividades didáticas, caracterizado como aquele que se distancia de uma organização temporal voltada para o estudo e para a reflexão ao identificar-se com um modelo de tempo culturalmente acelerado (REZENDE, 2015); e c) a centralidade da leitura e da escrita como objetos de ensino em aulas de estágio (RIBEIR0, 2015).

Como se vê, tais resultados sinalizam a diversidade das discussões, que se voltaram tanto aos aspectos formativos, com foco na análise de relatórios de estágio, quanto a elementos concernentes à atuação do professor responsável pelo campo do ensino de português em cursos de licenciatura. Ainda acerca dos aportes disciplinares em licenciaturas voltadas para o ensino de português, Souza, Pereira e Costa (2012, p. 104), ao analisar as ementas referentes ao ensino da língua em três instituições - UERN, USP e UFMA - afirmam que: "Em todas elas o texto aparece como unidade de ensino, afastando-se assim de modelos tradicionais e estruturalistas". Esse dado demonstra como, na formação do professor de português, ainda tem importância e faz-se presente o debate já bem instaurado na área no que diz respeito à centralidade do texto em contraposição a uma abordagem focada nos estudos normativos da gramática.

Esse resultado converge com o que foi apresentado por Eufrásio (2012) no artigo Metodologia do ensino de língua portuguesa no curso de pedagogia: mapeamento dos seus objetos e referenciais teóricos. Nele, a autora apresenta recorrências localizadas em programas de ensino do português de cursos de Pedagogia de cinco universidades públicas de Minas Gerais e, dentre os dados apresentados, demonstra que não houve uma mesma referência bibliográfica citada em todos os programas, mas que a obra mais referenciada, em metade dos programas analisados, foi $O$ texto na sala de aula: leitura e produção, de João Wanderley Geraldi (1984), que, como se sabe, teve uma grande importância nos estudos da área quanto à mudança de perspectiva de ensino da língua no sentido de valorização do texto enquanto unidade de ensino.

Como se vê, o projeto de pesquisa Disciplinas da licenciatura voltadas para o ensino de língua portuguesa promoveu a investigação a respeito do campo das recorrências no discurso sobre a formação e a atuação do professor de português e sobre a função disciplinar desempenhada por tais regularidades. 0 presente artigo busca trazer mais 
uma contribuição nesse sentido, voltando-se para a análise de dissertações de mestrado, conforme anunciado anteriormente. As dissertações analisadas aqui também colaboram para a reflexão acerca da formação desse professor de língua na medida em que podem repercutir como leitura direta ou pela atuação de seus autores nessa formação.

Para analisar o corpus, alinhamo-nos ao paradigma indiciário, conforme exposto por Carlo Ginzburg (1989), por voltarmos a nossa análise às invariantes discursivas, entendendo-as como indiciadoras do que caracteriza o discurso enquanto não-dito. Metodologicamente, a presente investigação também pode ser associada à pesquisa de tipo bibliográfica. A esse respeito, esclarecemos nossa concordância com Lima e Mioto (2007, p. 38) quando enfatizam que a pesquisa bibliográfica não se define como uma revisão da literatura:

Isto acontece porque falta compreensão de que a revisão de literatura é apenas um pré-requisito para a realização de toda e qualquer pesquisa, ao passo que a pesquisa bibliográfica implica em um conjunto ordenado de procedimentos de busca por soluções, atento ao objeto de estudo, e que, por isso, não pode ser aleatório.

0 interesse de pesquisa que, dentre outros resultados, culminou na escrita deste artigo reflete nossa avaliação de que, se por um lado, o ensino de português nas escolas de educação básica é motivo de constante interesse de pesquisa e discussão, por outro, ele ainda não desfruta de avanços que potencialmente poderiam ser alcançados pela parceria escola-universidade em processos de pesquisa acadêmico-científica. Como se verificará no que segue, defendemos que tais avanços, por vezes, não se concretizam porque a produção investigativa da área obedece a paradigmas que têm norteado interpretações homogeneizadoras da realidade de ensino pesquisada. Isso permite defender ainda que parte da responsabilidade pelos alegados poucos avanços no ensino de português seja creditada ao modo como se procede na pesquisa e escrita acadêmica a respeito do ensino de português.

\section{Análise da produção discursiva sobre ensino de língua portuguesa}

Conforme exposto, na análise do corpus buscamos identificar as regularidades constituintes do discurso, de acordo com a concepção de que todo discurso responde a determinadas condições de produção, a regras de funcionamento que definem o que é legítimo enquanto circulação de saberes que, por sua vez, sustentarão práticas diversas, dentre elas a científica. Nesse contexto de investigação, um dos resultados a que chegamos foi a identificação da negação como uma regularidade discursiva constituinte das dissertações analisadas.

Essa negação configurou-se na descrição e apresentação de realidades que só existiam enquanto criações científicas. Ou seja, observamos o procedimento recorrente em pesquisas em ensino de português na educação básica de remissão a uma situação educativa tida como ideal, mas como irreal, porque ela era apresentada como ideal 
no interior de uma negação que demonstrava o seu não comparecimento na prática docente observada.

A esse respeito, esclarecemos que fazemos referência a dissertações de mestrado que incluíam a pesquisa observante em sua metodologia. Nelas, a investigação contava com a observação de aulas de português e, ao transformarem-se as informações coletadas em dados para análise, regularmente ocorria o processo de apresentação do que poderia ter acontecido em sala de aula (realidade ideal) no interior de uma negação que demonstrava que ela efetivamente não tinha ocorrido.

Como exemplo, citamos o trecho a seguir:

Constatamos até aqui que os textos em sala de aula vêm sendo tratados de maneira bastante superficial. A professora, provavelmente por não ter conhecimento teórico sobre gêneros textuais, também não aborda os aspectos essenciais dos gêneros que estão sendo apresentados pelo livro didático. Além disso, os alunos desconhecem o suporte (jornal) no qual esses textos (a tira, as manchetes e os editoriais) estão inseridos. Todos esses aspectos envolvidos deságuam na dificuldade de construção de sentidos em sala de aula, e como conseqüência, prevalece sempre a voz da professora. Isso é muito evidente principalmente durante a discussão desse primeiro editorial, "Multa contra a dengue." (FPB07, grifo do original). ${ }^{7}$

0 trecho foi extraído de dissertação de mestrado que apresentou resultados decorrentes da observação, em especial quanto ao tema da leitura, de aulas de português em escola pública de Campina Grande/PB e foi defendida em Instituição Federal do estado em 2007. A passagem sublinhada destaca a situação educativa formulada pela pesquisa em questão - quanto à abordagem de "aspectos essenciais dos gêneros" - que está inserida em uma negação que atesta a inexistência dessa realidade pedagógica nas aulas observadas.

Nesse caso, a situação educativa ideal aparece explicitamente relacionada à formação docente. Caso a professora tivesse um conhecimento teórico sobre gêneros textuais, teria condições de materializar em aula a abordagem dos "aspectos essenciais dos gêneros apresentados pelo livro didático”. Nesse excerto de FPB07, destacamos uma situação educativa que estamos caracterizando como criação científica e que, discursivamente, integra a negação da sua existência nas aulas observadas, significando que aquilo que corresponde ao defendido pela dissertação em questão não é observável no cotidiano escolar.

Com esse termo, criação científica, aproximamo-nos das considerações de Chauí (2001, p. 23) que, ao caracterizar historicamente o fazer científico, apresenta a ciência moderna a partir da sua crença em uma realidade que poderia ser descrita e que poderia sofrer a ação do homem, ao contrário da ciência contemporânea, que:

7- No código apresentado após as transcrições de fragmentos das dissertações analisadas, a primeira letra refere-se ao vínculo administrativo da Instituição de Ensino Superior (IES) a que o trabalho está vinculado, considerando IES municipais, estaduais ou federais. A seguir, é apresentada a sigla referente ao Estado da IES e, por fim, 0 ano de defesa da dissertação. No caso de FPB07, por exemplo, indicamos que a dissertação foi defendida em IES Federal da Paraíba, em 2007. Decidimos não listar as referências completas de cada uma das dissertações, porque 0 interesse de investigação voltou-se para a discussão de regularidades na produção acadêmica quando analisada em conjunto e não quando tomada separadamente. 
[...] acredita que não contempla nem descreve realidades, mas a constrói intelectual e experimentalmente nos laboratórios. Essa visão pós-moderna da ciência como engenharia e não como conhecimento, desprezando a opacidade do real e as difíceis condições para instituir as relações entre o subjetivo e o objetivo, leva à ilusão de que os humanos realizariam, hoje, o sonho dos magos da Renascença, isto é, serem deuses porque capazes de criar a própria realidade e, agora, a própria vida. (CHAUÍ, 2001, p. 23, grifo da autora).

0 paralelo que realizamos é com essa ideia de realidade que existe enquanto criação científica. No presente caso, não nos referimos a pesquisas de laboratório, mas a pesquisas que, para manifestarem-se contrariamente ao que foi observado em contexto real de ensino da educação básica, apresentam, como alternativa, situações educativas que correspondem a determinadas concepções teórico-metodológicas e que têm a sua existência circunscrita ao universo investigativo do qual a dissertação de mestrado é decorrente.

Lembramo-nos também da noção cinematográfica de ficção científica, que, geralmente, é lida com conceitos ficcionais e imaginativos e caracteriza-se por sua natureza especulativa quanto ao futuro do mundo, em que as sociedades e os indivíduos enfrentam desastres e outros fenômenos decorrentes de situações relacionadas à ciência e à tecnologia. Trata-se de interpretações especulativas acerca de uma realidade inexistente, consoante à caracterização do gênero como aquele "que mais especula sobre as consequências da tecnociência para a humanidade” (TORRES, 2017, p. 95).

Nos trabalhos analisados, as situações educativas são apresentadas no interior de uma negação que atesta a sua inexistência, a não-efetivação dessa realidade nos contextos escolares de ensino básico. A negação de uma realidade que só existe enquanto criação científica também nos provoca a considerar as apreciações de Michel Foucault no livro Isto não é um cachimbo (1988). Nele, como o seu título demonstra, o autor volta-se para algumas reproduções de quadros do pintor René Magritte. Dentre elas, destaca-se aquela em que a figura de um cachimbo e a inscrição Ceci n'est pas une pipe estão postos no interior de uma moldura, que, por sua vez, apoia-se sobre um cavalete. Acima dessa moldura, há outro cachimbo, igual ao primeiro, mas maior em tamanho.

Destaca-se, desse livro, a seguinte afirmação:

Voltemos a esse desenho de um cachimbo que se assemelha tanto a um cachimbo; a esse texto escrito que se assemelha, tão exatamente, ao desenho de um texto escrito. De fato, lançados uns contra os outros ou mesmo simplesmente justapostos, esses elementos anulam a semelhança intrínseca que parecem trazer consigo, e pouco a pouco se esboça uma rede aberta de similitudes. Aberta, não para o cachimbo "real", ausente de todos esses desenhos e de todas essas palavras, mas aberta para todos os outros elementos similares (compreendendo nisso todos os cachimbos "reais", de barro, de escuma, de madeira etc.) que, uma vez tomados nessa rede, teriam lugar e função de simulacro. E cada um dos elementos de "isto não é um cachimbo" bem poderia manter um discurso em aparência negativo, pois se trata de negar, com a semelhança, a asserção de realidade que ela comporta, mas que é no fundo afirmativo: afırmação do simulacro, afırmação do elemento na rede do similar. (FOUCAULT, 1988, p. 64-65). 
Como se vê, essa citação analisa a presença do "cachimbo" e do "texto escrito" na obra de René Magritte, chamando a atenção para a rede de similitudes existentes entre o desenho e aqueles que seriam os "cachimbos reais". Se entre a figura desenhada e o objeto em si, há um simulacro em jogo, o mesmo ocorre quanto ao "texto escrito", pois, por meio da negação, o simulacro comparece como sendo aquilo que se afirma, isto é, afirma-se que ali existe a simulação do que poderia ser um "cachimbo".

Ao trabalharmos sobre o nosso corpus, foi-se evidenciando que a negação aparecia como constituinte do discurso de pesquisa em ensino de língua portuguesa e que o objeto da negação era a realidade criada no interior da pesquisa. 0 fragmento de dissertação citado anteriormente dá exemplo desse tipo de criação da realidade, inserida em uma negação que, discursivamente, apresenta as situações educativas ideais como inexistentes nos contextos escolares observados. Os excertos que passamos a apresentar também trazem negações de realidades pedagógicas defendidas no interior da pesquisa. Para discussão, citamos os que seguem:

As redações das escolas não incentivavam a escrita, porque não possuíam correspondência com o mundo real nem destinatário real. Eram escritas para o professor não como uma pessoa a quem se comunica algo, mas como avaliador. Segundo Geraldi (2003, p. 128)', "na redação, não há um sujeito que diz, mas um aluno que devolve ao professor a palavra que lhe foi dita pela escola."(FMT06).

Defendida em 2006, em Universidade Federal do Mato Grosso, a dissertação de que foi retirado o trecho anterior apresentou dados oriundos de observação de aulas em uma quinta série de escola municipal de Rondonópolis/MT e, como se verifica, um dos enfoques discutidos foi o ensino de escrita. A situação educativa que ganha realidade no interior do trabalho é aquela que incentivaria a escrita em um contexto de correspondência com o mundo real e com destinatários reais. Fica evidenciado, pelo procedimento da negação, que essa situação ideal foi inexistente nas aulas observadas.

De maneira similar, no excerto que segue também é feita a negação de uma realidade tida como ideal no ensino de português, descrita como aquela na qual o aluno seria considerado "um ser ativo e interativo":

0 que presenciamos em sala de aula parece ser orientado pela visão de que o aluno aprende por si mesmo porque, com exceção das aulas da EF2, não há situações em que o aluno seja tomado como um ser ativo e interativo no processo, como aquele que aprende por meio da interação com o professor, com os outros colegas e com os demais membros de seu grupo social, os quais atuam como mediadores entre a cultura e o indivíduo. (FPA07, grifo do original).

Nessa dissertação, o objetivo foi investigar a relação entre o professor e o livro didático na quarta série do Ensino Fundamental em seis escolas de Belém/PA. Um dos

8- Citação, em FMT06b, a GERALDI, João Wanderley (Org.). o texto na sala de aula. 3. ed. São Paulo: Ática, 2003. 
enfoques foi identificar estratégias utilizadas pelas professoras no momento em que usavam o livro didático.

0 fragmento a seguir foi retirado de dissertação que analisou processos de formação docente continuada, os quais tinham na sua base os Parâmetros Curriculares Nacionais como objeto de estudo. Um dos pontos de discussão voltou-se para o ensino da oralidade em aulas de português. No tocante a isso, localizamos no excerto a exposição de uma situação educativa incorporada à sua negação enquanto objeto de preocupação das docentes que foram entrevistadas pelo pesquisador:

De modo geral, as falas das professoras demonstraram uma concepção de oralidade bastante restrita. Não há preocupação com as regras sociais que estão em jogo nas mais diversas situações comunicativas. Quando as professoras descrevem como trabalham a oralidade, sempre buscam a homogeneização da fala e da escrita, segundo a norma culta escrita. (EPA08).

0 trabalho de que citamos a seguir um trecho teve como foco a análise de propagandas, quanto à sua aparição em livros didáticos e ao seu uso por professoras de séries iniciais de uma escola de Viçosa/MG. Nele, evidenciam-se as situações educativas formuladas pelo trabalho como desejáveis - melhor exploração da propaganda presente no livro didático em questão - no interior das negações que demonstram a inexistência dessa realidade nos contextos de aula observados:

Lamento relatar que a professora "S" não tenha aproveitado aquele momento da relação ensinoaprendizadem para explorar melhor a propaganda no sentido de mostrar que esta não está inserida em uma revista nem em um jornal, por exemplo, mas no interior de um livro didático. Pude observar também que ela não aproveitou esse rico momento de interação com seus alunos para explorar qual teria sido a intenção das autoras do livro didático em ter escolhido essa propaganda para ser utilizada em sala de aula. (ESP12).

Encerramos o conjunto de dados transcritos nesta seção com o fragmento a seguir:

A compreensão que obtivemos destas atividades propostas pelo LDP, é que, apesar de algumas exceções como as citadas, não há preocupação em levar o aluno a perceber os efeitos de sentido provocados pela leitura do texto. Não é notório, neste caso, um direcionamento de exercícios que leve o aluno a tomar a linguagem como objeto de reflexão, no sentido apontado pelos PCNs de língua portuguesa (1997, p. 78), que teriam como "objetivo principal melhorar a capacidade de compreensão e expressão dos alunos em situações de comunicação tanto escrita como oral”. (FG017).

Esse excerto demonstra uma das análises de livros didáticos realizadas pela dissertação sob enfoque, que teve como objetivo tratar do uso de tais livros na prática docente de ensino de português nos anos iniciais do Ensino Fundamental. Nele, verifica-se uma realidade pedagógica - que seria a de "levar o aluno a perceber os efeitos de sentido provocados pela leitura do texto" e de levar "o aluno a tomar a linguagem como objeto 
de reflexão" - que se circunscreve à sua formulação enquanto possibilidade de ensino no interior do trabalho investigativo em questão, mas que é, pela negação, exposta como inexistente nos materiais analisados.

Os fragmentos expostos denotam aquilo que verificamos como um modus operandi em dissertações de mestrado que tratam do ensino de português nas escolas de educação básica. Verificamos nas dissertações a reiteração de um mesmo procedimento, o de apresentar uma situação educativa defendida como ideal no ensino de português e incorporá-la à negação de sua real existência, destacando a sua não efetivação nas aulas observadas em contexto de pesquisa.

\section{A negação polêmica}

A negação constituinte do discurso acadêmico sobre ensino de português, tendo em vista as dissertações analisadas, caracteriza-se pela polêmica entre dois pontos de vista. Tal polêmica demonstra o embate entre a perspectiva de ensino do/a pesquisador/a e aquela que é exposta como fruto da observação de sala de aula.

No Esboço de uma teoria polifônica da enunciação, Ducrot (1987) distingue três tipos de negação, classificadas como negação metalinguística, negação descritiva e negação polêmica.

A primeira é caracterizada por contradizer os termos da formulação a que se opõe. Em um exemplo como "Pedro parou de fumar", o que seria negado seria a própria palavra "parou" em uma argumentação como "Pedro nunca fumou e, assim, não pode ter parado". A segunda remete à representação de um estado de coisas, sem que haja oposição a outro discurso. Essa negação, de tipo "descritivo", exemplifica-se na resposta de que "não há nenhuma nuvem no céu" à pergunta de outro locutor sobre as condições climáticas observadas. A terceira é considerada majoritária e é caracterizada como sendo aquela que inclui no próprio enunciado o ponto de vista rejeitado. A explicação para isso é que o locutor não faz oposição a outro locutor, ele nega um enunciador (o ponto de vista) que ele próprio insere no seu discurso. Por meio do exemplo "Pedro não é gentil", defende-se que a atitude positiva que é rejeitada pelo locutor, no caso, "Pedro é gentil", é interna ao discurso (DUCROT, 1987, p. 203-204).

É válido situar que Ducrot (1987) volta-se para o enunciado a partir de uma concepção polifônica da enunciação, fundamentada por pressupostos bakhtinianos, e segundo a qual todo "enunciado assinala, em sua enunciação, a superposição de diversas vozes" (DUCROT, 1987, p. 172) que são, na análise ducrotiana, categorizadas como "sujeito no mundo", "locutor" e "enunciador". Para a sua teoria, interessam as duas últimas posições, mas não a primeira, identificada como a do "sujeito no mundo" ou "sujeito empírico", que se refere a uma pessoa específica no mundo.

0 locutor é definido como o "sujeito do discurso", como fonte de enunciação que será responsabilizada pelo "eu” que é dito. Trata-se da instância responsável pela materialidade linguística. 0 enunciador é, por sua vez, retratado como o "centro de perspectiva", isto é, como o "ponto de vista". 0 tratamento polifônico do "enunciado" advém de que, como 
mostram exemplos de ironia e de negação, pontos de vista apresentados no interior da enunciação podem ser rejeitados pelo locutor.

Foucault, ao tratar dos "enunciados", também considera a dispersão de vozes passíveis de serem configuradas em uma enunciação, mas se volta a eles tendo em vista um "diz-se", ou seja, as condições de possibilidade concretizadas na produção de um discurso. 0 "enunciado" enquanto "condição de existência", que permite que certa ideia seja manifestada em um dado momento, remete ao a priori kantiano, que pode ser relacionado ao a priori histórico de Foucault, que Deleuze (2005, p. 69), por sua vez, chamará de "neo-kantismo".

0 "enunciado" foucaultiano propicia a reflexão sobre as coerções discursivas, mas não sobre aquelas situadas no nível da língua. Tomamos, assim, o referencial trazido pela teoria de Ducrot e colaboradores a fim de expor o funcionamento da negação na constituição das polêmicas que fundam um saber no campo de pesquisa sobre o ensino do português na educação básica. Buscamos, assim, evidenciar formulações linguísticodiscursivas legitimadas na produção científica em questão.

No que segue, transcrevemos outros dados retirados do material analisado, os quais dão a ver o funcionamento da negação polêmica na produção discursiva sob enfoque. Os excertos citados anteriormente dão exemplos desse tipo de negação, e, no que segue, detalhamos tal fenômeno pela visualização dos enunciadores em jogo, dada sua polifonia característica, e buscamos apontar para os focos de polêmica veiculados pelas negações:

1) Constatamos também, que os textos revisados e reescritos nas primeiras aulas não foram tratados pela professora como unidade complexa de comunicação e de significação, destinado [sic] a um interlocutor que com ele deveria interagir. Nesses casos o texto serviu apenas como pretexto para exercícios gramaticais [...]. (EPR02).

2) A atitude dos alunos de esperar "a leitura correta" nos evidencia que, tanto professora quanto alunos, não trabalham com textos numa perspectiva sócio-interacionista de leitura em que mais de um sentido é permitido para os textos. (FPB07).

3) Os conteúdos, nos editoriais trabalhados em sala de aula, estavam relacionados a assuntos que os alunos conheciam (epidemia de dengue e novas tecnologias). Do ponto de vista da textualidade, seria importante o destaque para a estrutura composicional e o estilo desses textos, relacionando-os aos suportes onde eles circulam, à função social que eles exercem e ao público ao qual se destinam. Todo esse percurso suscitará, naturalmente, sentidos na leitura. E essa abordagem não aconteceu justamente porque a professora parece não ter um conhecimento teórico mais aprofundado sobre os gêneros textuais. (FPB07).

4) [...] podemos concluir que embora os gêneros discursivos estejam presentes nesses instrumentos didáticos [Referência aos livros analisados], eles não são tomados como objeto, uma vez que os aspectos ligados à situação de produção, os elementos da ordem do social e do histórico, o conteúdo temático, a construção composicional e o estilo verbal não são 
tratados de modo sistemático. Percebemos que eles são suportes de conteúdos e favorecem o desenvolvimento de várias atividades que levam as professoras a intervir sobre a temática, daí afırmarmos que as informações veiculadas no texto são os objetos de ensino priorizados nas propostas do LD. (FPA07).

5) Nas estratégias para o desenvolvimento de atividades de escrita fica evidente a preocupação com as correções e inadequações em relação ao padrão estabelecido. Não há preocupação com a utilização de mecanismos discursivos e lingüísticos de coerência e coesão textuais, conforme o gênero e o propósito do texto. 0 objeto de estudo da língua portuguesa ainda é língua em sua variedade culta, deixando-se de considerar a língua como um fato social. (EPA08).

Desses excertos, depreendemos os pontos de vista positivos internos aos enunciados de negação:

1) os textos revisados e reescritos nas primeiras aulas foram tratados pela professora como unidade complexa de comunicação e de signifıcação, destinados a um interlocutor que com ele deveria interagir;

2) tanto professora quanto alunos trabalham com textos em uma perspectiva sociointeracionista de leitura em que mais de um sentido é permitido para os textos;

3) essa abordagem aconteceu justamente porque a professora parece ter um conhecimento teórico mais aprofundado sobre os gêneros textuais;

4) eles são tomados como objeto, uma vez que os aspectos ligados à situação de produção, os elementos da ordem do social e do histórico, o conteúdo temático, a construção composicional e o estilo verbal são tratados de modo sistemático; e

5) há preocupação com a utilização de mecanismos discursivos e linguísticos de coerência e coesão textuais, conforme o gênero e o propósito do texto.

Observa-se que esses pontos de vista positivos são internos ao discurso que materializa a negação, instaurando, assim, a polêmica entre diferentes enunciadores, representantes de pontos de vista inconciliáveis, que rivalizam entre o que deveria ser e 0 que de fato aconteceu em sala de aula.

Tal polêmica evidencia perspectivas de embate no campo de pesquisa sobre ensino de português. Nos dados citados em 1) e 2), a abordagem dos textos com objetivo de estudos gramaticais e de decifrar-lhe o sentido único é inaceitável pelo locutor do texto quanto ao que ele defende como atuação docente desejável, no caso embasada por perspectivas de caráter interacionista. Em 3), 4) e 5), os locutores destacam a ausência de tópicos como estrutura composicional, estilo e função social e a prioridade à língua escrita padrão como inaceitáveis no ensino de língua portuguesa, conforme o que foi defendido na perspectiva do estudo dos gêneros.

Esse resultado, somado ao que foi exposto até aqui, indicia que a negação de situações educativas balizadas por um conjunto de preceitos teórico-metodológicos, quanto à sua não-presença no contexto escolar, é uma das condições de produção do discurso acadêmico sobre ensino de português. Conforme tratado, caracterizamos essa 
negação como polêmica por instaurar, de acordo com o referencial ducrotiano, o embate entre dois enunciadores que são internos ao discurso. Quanto às análises que apresentamos do corpus, avaliamos que a abordagem científica que contrapõe a realidade escolar ao que é defendido academicamente traz poucas contribuições à renovação do conhecimento produzido pela área, uma vez que tal contraposição é tida como algo já consolidado pelas pesquisas que tratam do ensino de português na educação básica.

\section{Considerações finais}

Conforme as análises apresentadas, identificamos a negação polêmica como uma condição de produção do discurso acadêmico sobre ensino de língua portuguesa. Essa negação funcionou como uma "variável constante" (DELEUZE, 2005). Ou seja, havia uma variabilidade quanto à realidade de ensino observada - haja vista que cada uma das dissertações analisadas apresentou dados oriundos da observação de diferentes contextos de ensino de português -, contudo havia uma constância no procedimento de apresentar a situação educativa defendida pela sua negação, ou seja, pelo apontamento de sua não efetivação na realidade de ensino observada e pela hipotetização de que se o professor fizesse de certo modo ou lesse determinado referencial teria sido concretizada uma situação ideal de ensino de português.

Isso leva-nos à reflexão de como a polêmica também pode ser consensual. Explicando: o referido consenso não se localiza na polêmica em si (no que ela nega), mas na legitimação e decorrente repetição desse procedimento linguístico-discursivo de negar a existência de determinadas situações educativas na realidade escolar, sendo que tais situações correspondem exatamente ao ponto de vista então defendido nos trabalhos analisados.

Os resultados demonstraram que as negações polêmicas responderam ao mesmo padrão de inserir como ponto de vista positivo as propostas de ensino almejadas, relacionadas às referências teórico-conceptuais legitimadas, e negá-lo tendo em vista o que se apresentava como fruto do que foi observado em salas de aula da educação básica.

Tal constatação indicia um modus operandi na produção acadêmica a respeito de ensino de português que se realiza pela refutação do cotidiano escolar observado em nome de situações educativas idealizadas. Assim, fica sinalizado que, ao constituir recorrentemente a produção sob enfoque, a negação polêmica apresenta-se estabilizada, ou seja, já está dado que a realidade escolar não corresponde ao que é legitimado cientificamente. De modo que, nos casos analisados, a polêmica instaurada entre dois pontos de vista diferentes perde o seu potencial questionador.

Quando Thomas S. Kuhn, em A Estrutura das revoluções cientificas (1987), referese à ciência normal, ele destaca a permanência de paradigmas que são seguidos pela comunidade acadêmica de uma dada área do saber. Como interrupção a essa ciência, vêm as revoluções científicas, caracterizadas como a modificação de um paradigma a outro.

Quanto à produção acadêmica acerca do ensino de português na educação básica, fica o indício de que entre a afırmação de um paradigma - as concepções teóricas hegemônicas que sustentam propostas atuais para o ensino em questão - e a sua negação como inexistente, não-hegemônica ou incorreta no âmbito escolar, fica faltando o 
ponto da evolução científica em que os paradigmas que se propõem para a atualidade sustentem-se em si próprios, exclusivamente por sua coerência teórico-metodológica e/ ou por sua efetivação enquanto pesquisa-ação, sem terem de remeter-se à argumentação sobre sua ausência, ou seja, a de que ali não está bom porque as concepções de ensino então defendidas não estão presentes da forma que deveriam. Com isso, enfatizamos que o tipo de pesquisa observante que, quanto ao ensino de língua portuguesa, demonstra a não-correspondência entre o que se defende academicamente e o que se verifica no ensino da educação básica já cumpriram um papel importante ao retratarem realidades que mereciam ser pesquisadas e isso já está dado pela produção acadêmica sob enfoque.

\section{Referências}

ALMEIDA, Sonia. Objetivos de projetos político-pedagógicos: lugar de acontecimento discursivo. In: SOUSA, Antonio Paulino de; BARZOTTO, Valdir Heitor; SAMPAIO, Maria Lúcia Pessoa (Org.). Formação de professores de língua portuguesa: quando a linguagem e o ensino se encontram. 1. ed. São Paulo: Paulistana, 2010. p. 127-139.

BARZOTTO, Valdir Heitor. Modalizações em torno da prática e cristalização da imagem do professor de língua portuguesa. In: SOUSA, Antonio Paulino; BARZOTTO, Valdir Heitor; SAMPAI0, Maria Lúcia Pessoa (Org.). Formação de professores de língua portuguesa: quando a linguagem e 0 ensino se encontram. 1. ed. São Paulo: Paulistana, 2010. p. 9-19.

BRASIL. Ministério da Educação. Coordenação de Aperfeiçoamento de Pessoal de Nível Superior. Plano Nacional de Pós-Graduação: PNPG 2011-2020. v. 1. Brasília, DF: Capes, 2010. Disponível em: <http:// www.capes.gov.br/images/stories/download/Livros-PNPG-Volume-I-Mont.pdf>. Acesso em: fev. 2018.

BRASIL. Ministério da Educação. Coordenação de Aperfeiçoamento de Pessoal de Nível Superior. Comissão Especial de Acompanhamento do PNPG 2011-2020. Relatório final 2016. Brasília, DF: CAPES, 2017. Disponível em: <https://www.capes.gov.br/images/stories/download/relatorios/231117-Relatorio-PNPGFinal-2016-CS.pdf>. Acesso em: fev. 2018.

CHAUÍ, Marilena de Souza. Escritos sobre a universidade. São Paulo: Edunesp, 2001.

DELEUZE, Gilles. Foucault. São Paulo: Brasiliense, 2005.

DUCROT, Oswald. 0 dizer e o dito. Campinas: Pontes, 1987.

EUFRÁSI0, Daniela Aparecida. Metodologia do ensino de língua portuguesa no curso de pedagogia: mapeamento dos seus objetos e referenciais teóricos. Espaço Plural, Marechal Cândido Rondon, v. 13, p. 100-109, 2012.

EUFRÁSIO, Daniela Aparecida. 0 ensino de língua portuguesa e sua configuração disciplinar em dissertações de mestrado. 2013. 336 f. Tese (Doutorado em Letras) - Faculdade de Filosofia, Letras e Ciências Humanas, Universidade de São Paulo, São Paulo, 2013.

FOUCAULT, Michel. A ordem do discurso. 11. ed. São Paulo: Loyola, 2004. 
FOUCAULT, Michel. Arqueologia do saber. 7. ed. Rio de Janeiro: Forense Universitária, 2005.

FOUCAULT, Michel. Isto não é um cachimbo. Rio de Janeiro: Paz e Terra, 1988.

GERALDI, João Wanderley (Org.). 0 texto na sala de aula: leitura \& produção. Cascavel: Assoeste, 1984.

GINZBURG, Carlo. Sinais: raízes de um paradigma indiciário. In: GINZBURG, Carlo. Mitos, emblemas, sinais: morfologia e história. São Paulo: Companhia das Letras, 1989. p. 143-179.

KUHN, Thomas S. A estrutura das revoluções científicas. 2. ed. São Paulo: Perspectiva, 1987.

LIMA, Telma Cristiane Sasso de; MIOTO, Regina Célia Tamaso. Procedimentos metodológicos na construção do conhecimento científico: a pesquisa bibliográfica. Revista Katálysis, Florianópolis, v. 10, n. spe, p. 37-45, 2007. Disponível em: <http://www.scielo.br/scielo.php?script=sci_arttext\&pid=S1414$49802007000300004 \&$ lng=en\&nrm=iso >. Acesso em: mar. 2018.

MILADA. Direção David Mrnka. República Tcheca, 2017.

REVEL, Judith. Michel Foucault: conceitos essenciais. São Carlos: Claraluz, 2005.

RIBEIRO, Nilsa Brito. De objetos de ensino à formação do professor de português. In: RIOLFI, Claudia Rosa (Org.). Professor de português: como se forma, trabalha e entende sua prática. 1. ed. São Paulo: Paulistana, 2015. p. 125-145.

REZENDE, Neide Luzia de. Tempo e ritmo das atividades escolares de linguagem. In: RIOLFI, Claudia Rosa (Org.). Professor de português: como se forma, trabalha e entende sua prática. 1. ed. São Paulo: Paulistana, 2015. p. 113-123.

RIOLFI, Claudia Rosa (Org.). Professor de português: como se forma, trabalha e entende sua prática. 1. ed. São Paulo: Paulistana, 2015.

RIOLFI, Claudia Rosa; EUFRÁSI0, Daniela; BAZON, Fernanda Vilhena Mafra. Figurações da disciplina metodologia do ensino de língua portuguesa. In: RIOLFI, Claudia Rosa (Org.). Professor de português: como se forma, trabalha e entende sua prática. v. 1. 1. ed. São Paulo: Paulistana, 2015. p. 15-34.

SOUSA, Antonio Paulino de. Didática e metodologia: percursos históricos e constituição de disciplinas. In: SOUSA, Antonio Paulino de; BARZOTTO, Valdir Heitor; SAMPAIO, Maria Lúcia Pessoa (Org.). Formação de professores de língua portuguesa: quando a linguagem e o ensino se encontram. 1. ed. São Paulo: Paulistana, 2010. p. 33-58.

SOUSA, Antonio Paulino de; BARZOTTO, Valdir Heitor; SAMPAI0, Maria Lúcia Pessoa (Org.). Formação de professores de língua portuguesa: quando a linguagem e o ensino se encontram. 1. ed. São Paulo: Paulistana, 2010.

SOUZA, Gilton Sampaio de; PEREIRA, Crígina Cibelle; COSTA, Elvis Alves da. 0 objeto de ensino de língua 
portuguesa em disciplinas do curso de letras de universidades brasileiras. In: SAMPAI0, Maria Lúcia Pessoa; REZENDE, Neide Luzia de; BONFIM, Maria Núbia Barbosa (Org.). Ensino de língua portuguesa: entre documentos, discursos e práticas. São Paulo: Humanitas, 2012. p. 97-110.

TORRES, Sonia. 0 antropoceno e a antropo-cena pós-humana: narrativas de catástrofe e contaminação. Ilha Desterro, Florianópolis, v. 70, n. 2, p. 93-105, ago. 2017. Disponível em: <http://www.scielo.br/scielo. php?script=sci_arttext\&pid=S2175-80262017000200093\&lng=en\&nrm=iso> . Acesso em: mar. 2018.

Recebido em: 11.04.2018

Revisões em: 21.08.2018

Aprovado em: 12.09.2018

Daniela Aparecida Eufrásio é professora no Instituto de Ciências Humanas e Letras da Universidade Federal de Alfenas (Unifal). Como principais linhas de pesquisa, investiga sobre produção de conhecimento em ensino de língua portuguesa, ensino de leitura e escrita, literatura infantil.

Valdir Heitor Barzotto é professor na Faculdade de Educação da Universidade de São Paulo (FEUSP). Como principais linhas de pesquisa, investiga sobre produção no ensino superior, leitura e escrita e metodologia do ensino de português. 